\title{
Rethinking Engineering Education Through a Leadership Perspective
}

\author{
Roger Green (Roger.Green@ndsu.edu) \\ Department of Electrical and Computer Engineering \\ North Dakota State University
}

\begin{abstract}
Many traditional engineering education environments operate according to an authority model where teachers (the authority) seek to educate students (the subordinates). Although the presence of an authority does not necessarily imply that an education system is authoritarian, teachers operating under an authority model often apply fear- and incentive-based control mechanisms to achieve desired educational goals and outcomes. These control mechanisms can achieve results but may also undermine classroom cohesion, encourage an adversarial atmosphere, and be less effective than alternate approaches such as those based on leadership training and research. This paper reconsiders engineering education through a leadership perspective where teachers voluntarily relinquish control, seek influence over authority, nurture cooperation over compliance, pursue projects and activities in partnership rather than in isolation, and work to establish an environment of mutual trust. These characteristics of leadership-based education are highly compatible with many current trends in university engineering programs, including the flipped classroom, problem-based learning, and on-line education, including massively open online courses (MOOCs).
\end{abstract}

\section{Background}

From kindergarten to graduate school, the vast majority of classroom experiences follow a traditional lecture format where a teacher delivers a mostly one-way communication of course content with minimal audience participation. Participation, when it does occur, often follows an initiation-response-follow-up (IRF) or similar model of questioning (see [1] for a discussion of classroom dialogue and interaction, including IRF). Traditional lectures are based on an authority model where the teacher (the authority) sets class rules, controls the nature and flow of information, and assigns and evaluates students' (the subordinates') work. Lecturing provides a practical and cost-effective method to educate large numbers of students. Despite recent trends away from lecture-based content delivery, at least one recent study suggests that lecture-style presentations can lead to higher student achievement than group problem-solving activities [2].

Most university professors, following decades of schooling, excel under a traditional lecture environment, which might partly explain why so many continue to follow the same format when teaching their own classes. While most conscientious instructors do, in fact, adopt new pedagogical techniques in an effort to improve student learning, one only needs to walk down the halls of most any university to observe that the traditional lecture format still reigns supreme. The lecture itself is an eight-hundred-year-old university tradition that, despite frequent criticism in recent years, is highly adaptable and likely to endure for years to come, albeit in continually modified or augmented forms [3].

The modification or augmentation of classroom and lecture structure deserves special consideration, particularly when contemporary changes diminish the effectiveness of traditional 
methods. Cultural and technological changes are certainly factors in today's changing educational landscape, something any seasoned instructor will have noticed in recent years. For example, today's students are generally less skilled in reading and writing, although they are more adept at nonconventional communication such as video. Compared to students just a decade or two ago, today's students are far less likely to utilize brick-and-mortar library resources, preferring to consult, often with high frequency, Google and the internet for information. Instant access to information enables today's students to enjoy a much broader view of topics, although this same instant availability to massive amounts of information may diminish students' self-reliance and ability to solve problems independently. Free access to information, on-demand entertainment, and an increasingly consumer-driven education model all contribute to a rising sense of entitlement on the part of students as well as instructors (see [4] for one instructor's observations on student entitlement).

There are also significant changes with regard to students' expectations and response to authority. While there are regional and other (for example, public versus private schools) differences, today's students are generally less tolerant of and less responsive to heavy-handed classroom authority. To provide a simple example, school corporal punishment, quite common in the United States during the 1900's, has (thankfully) experienced a rapid decline in recent decades [5]. Other changing attitudes toward authority are more subtle, making changes to classroom structure and organization less obvious.

The nature of classroom authority can be decidedly different, particularly between the pre- and post-secondary mark. Students at the primary and secondary education levels are typically minors and teachers often assume an in loco parentis role. Students at the post-secondary education level are generally adults and classroom authority requires appropriate adjustment. The focus of this paper is on post-secondary engineering education where instructors behave more as leaders than as parents. Recent trends and research in leadership provide excellent ideas to better guide engineering educators. Using a leadership perspective, Section II overviews authority, including characteristics that make authority effective. Section III discusses applying a leadership perspective to the classroom, including non-traditional venues such as the flipped classroom, problem-based learning, and on-line education, including massively open online courses (MOOCs). Conclusions are delivered in Section IV.

\section{II: A Leadership Perspective of Authority}

Although authority is a fundamental and necessary component of the classroom, it can also present difficulties and contradictions. As discussed by Sennett, people are simultaneously attracted to and repelled by authority [6]. People tend to admire strong leadership but resist (and resent) being told what to do. This point is compounded in higher education, which seeks to develop students' independence and free thought, characteristics that can be considered antithetical to classroom authority models.

To better understand authority in the classroom, it is important to recognize that authority takes different forms. Pace and Hemmings provide an excellent review of authority types including traditional, charismatic, legal-rational, professional, and moral authority [7]. Although teachers may employ different forms of authority in their classrooms, some are likely more effective than others. A teacher who relies heavily on traditional authority, expecting student obedience simply 
because they occupy the role of professor, may be less effective than a teacher who employs professional authority, which is largely derived from technical and pedagogical expertise. Even so, professional authority does not guarantee better results in the classroom than traditional authority. Regardless of type, the manner in which authority is exercised is critically important. In this context, leadership research and training can help inform more effective teaching practice.

Some leaders follow a style based on personal-dominance, sometimes called leader-based leadership and consistent with the first level of leadership described in [8]. This is commandand-control leadership where the leader imposes her or his will. Under this style, the leader sets organizational direction and priorities, takes action, and issues commands. It can be a somewhat authoritarian, even despotic, form of leadership. To achieve goals, subordinates are typically offered incentives, benefits, and rewards, although control can also be achieved by fear, threat, and coercion. Many professors manage their classrooms using this as their primary style.

While incentives and rewards are higher on the "hierarchy of persuasion" than threats and coercion (see [9]), these forms of persuasion tend to produce more short-term or temporary rather than long-term or permanent behaviors and results. Even when the leader provides incentives and rewards, the result tends to be compliance rather than true cooperation. Effective leaders, including teachers, should seek higher forms of persuasion.

Servant, or relationship-based, leadership is widely recognized as more effective than leaderbased leadership. Consistent with the second level of leadership described in [8], servant leadership is characterized by sharing power, seeking interpersonal influence over decree, putting the needs of others first, and developing commitment, motivation and a teamwork spirit. A servant-based leader works to align a group toward a common purpose and nurtures everyone to perform as highly as possible. Servant leaders tend to be empathetic, caring, and good listeners. In servant leadership, the focus is less on the leader and more on the team being led. Of course, many professors also employ elements of servant leadership in their classrooms, although perhaps not always by purposeful and planned action.

Servant leadership depends on developing a climate of trust and mutual respect. Without trust, achieving cooperation rather than compliance can be difficult, especially in educational settings. This connection to trust is explored in [7], which notes that "several educational sociologists and anthropologists have explored the dimension of trust, which is necessary for forging the kinds of affective bonds that generate obedience and the motivation to learn."

Since it so important to servant leadership and can sometimes seem so elusive to achieve, trust deserves special attention. Stephen Covey provides a two-dimensional model that illustrates trust as an intersection of both character and competence [10]. This is an important point that deserves repeating: trust requires both character and competence. Put another way, it is just as important how something is said (or taught) as what is said (or taught). Classroom success is not about competence alone; personal integrity, maturity, and a so-called abundance mentality (where sufficient resources exist for all to succeed, thereby encouraging cooperation and partnership over competition) are necessary components to establish a climate of trust. Engineering educators, who often focus on facts and figures (competence), need to pay special attention to the character component of trust. 
Although the primary focus of this paper is on the benefits of adopting servant rather than leaderbased leadership techniques, other leadership models exist that can offer worthwhile contributions to improved classroom operation. For example, much recent attention has been paid to adaptive leadership, described in [8] as level-three leadership, and adaptive leadership techniques can certainly be applied to an educational setting.

\section{III: Applying a Leadership Perspective to the Classroom}

This section discusses ways in which teachers can apply the ideas of servant leadership to their courses. The discussion here is meant to stimulate thought, not serve as a comprehensive tutorial on applying leadership principles to the classroom.

Awareness is the first step to change. From this perspective, Sections II and III provide a framework for any instructor to adjust their classrooms and teaching. Radical classroom changes or restructuring are possible but not necessary. Often, small improvements are easiest to accomplish. Changes should focus on 1) relinquishing control, 2) seeking influence over decree, 3) nurturing cooperation over compliance, and 4) working in partnership rather than isolation. Underlying each of these items is the development of a climate of mutual respect and trust.

\section{Establishing a Climate of Trust}

Engineers often focus their attention on the technical details of a problem, dismissing the "touchy-feely" aspects as irrelevant. Unsurprisingly, many engineering professors focus on the competence aspect of their courses and ignore or underemphasize the character aspect. Recalling that trust requires both competence and character, this is a recipe to undermine trust. According to Vincent Covello (Center for Risk Management), empathy, caring, and listening count approximately 50 percent toward a sense of trust (expertise, honesty, and commitment count for the other 50 percent) and, particularly in high-stress situations, trust characteristics are assessed in as little as 9 to 30 seconds. Thus, it is essential that educators develop - and develop quickly the character component of trust in their classrooms. There are many simple ways to help achieve this goal:

- Make time to listen to students, and hear what they have to say. Proactively ask students to express their thoughts, opinions, and feelings. Avoid rhetorical questions and instead engage students in meaningful conversation.

- While most instructors both care for and empathize with students, express these feelings during the classroom. If a homework or exam problem was particularly difficult, acknowledge the difficulty of the problem and sympathize with student frustrations. If students are faced with a particularly challenging week of homework or exams in their other courses, help accommodate these difficulties by delaying or reducing the work in your own course.

- A healthy sense of curiosity requires an open mind, which again encourages trust. Be curious about your students, their activities, current events, and recent developments that are relevant to your course.

- Clearly state your expectations and grading methods, and be consistent in their application. 
Another way to foster trust is for leaders to expose their own vulnerabilities. When students see that teachers make (and admit) mistakes, it is easier and safer for them to make (and admit) mistakes too. As most any engineer knows, mistakes are one of the surest ways to grow towards technical competence. Thus:

- Share stories where you made mistakes and how you grew from those mistakes. Make it safe for students to share their experiences and mistakes.

- Competence is not an excuse to be arrogant, particularly toward those with less experience. Display an appropriate sense of humility and admit when you don't know the answer to a problem or question.

While most professors are competent, trust is quite difficult in its absence. Thus:

- Ensure you are competent in what you teach, taking the necessary time to fully prepare for every lecture.

Of course, there are just as many ways to derail trust as to build it. Thus:

- Avoid being judgmental. When students share difficulties, failures, or incorrect answers, use these responses as learning opportunities.

- Avoid defensive, threatening, or accusatory language, any of which can destroy trust.

\section{Relinquish Control}

When professors relinquish (some) classroom control, students can become more engaged, assume more responsibility, and function more cooperatively. There are many ways to relinquish control to students. For example:

- Allow students free choices, such as selecting project topics, supplemental reading, and areas for class study.

- Involve students in deciding class structure, such as homework due dates, classroom balance between lecture and discussion, and frequency and type of group activities. Solicit student input on course syllabi during the first day of class.

By their very nature, many non-traditional educational methods automatically relinquish control, which may explain, to some extent, their popularity and effectiveness. For example:

- By moving lectures outside of the classroom, flipped classrooms and on-line courses allow students to control the time and pace that they process class materials.

- Many massively open on-line courses (MOOCs) relinquish some level of grade control by requiring students to evaluate other students' work.

\section{Seek Influence over Authority}

It is largely self-evident that influence is preferable to authoritarian demand. Influence requires mutual respect and trust as well as relinquished control, all previously discussed. That is:

- Work to establish a climate of trust in your class. When possible, cede control to your students and avoid using demands.

- Know your students names and learn something about each student. It is easier to influence someone you know than a stranger.

\section{Nurture Cooperation over Compliance}


Since it builds cohesion and tends to produce more long-lasting or permanent results, cooperation is preferable to compliance. As with influence, cooperation requires trust and shared responsibility.

- To build class cohesion and encourage cooperation, utilize humor or tell personal stories.

- Discussion boards, typical of on-line classes including MOOCs, provide students a venue for cooperation.

\section{Work in Partnership rather than Isolation}

Working as partners rather than competitors can increase cohesion and reduce an adversarial classroom atmosphere. Some ways to encourage partnership include:

- Provide pathways for students to make meaningful contributions to research or community projects.

- Seek inter-classroom or cross-disciplinary experiences for students.

Again, non-traditional educational methods often foster partnership:

- Problem-based learning naturally encourages students to work in partnership.

- In flipped classrooms, where class time is spent working on problems rather than lecture, students and instructors frequently work in partnership to solve problems.

\section{IV: Conclusions and Future Directions}

The lecture is a longstanding, primary mechanism to educate students. Although highly adaptable, the effectiveness of the lecture is impacted by contemporary cultural and technological changes as well as students' expectations and response to authority, factors that suggest adjustments in classroom organization and implementation are worth consideration. By adopting a leadership perspective to education, particularly a servant leadership model, classroom effectiveness can be improved. To achieve this goal, instructors should develop a climate of trust, relinquish classroom control, seeking influence over decree, nurture cooperation over compliance, and work toward classroom partnerships. Many of these characteristics occur naturally with contemporary educational formats such as the flipped classroom, problem-based learning, and on-line education.

While the characteristics and advantages of servant leadership are well established, future study is needed to establish its applicability to the engineering classroom and its impact on classroom effectiveness. To this end, the author welcomes any ideas, suggestions, and potential partners.

\section{Acknowledgement}

The author would like to acknowledge Ruben Fernandez (JD) and Claudia Plaisted Fernandez (DrPH, MS, RD, LDN) whose FastTrack Leadership seminars and training (http://www.wetrainleaders.com/) helped originate and inspire the ideas in this paper.

\section{References}

[1] Wells, Gordon, "Dialogue in the Classroom," The Journal of the Learning Sciences, Vol. 15, No. 3, pp. 379-428, 2006.

[2] Schwerdt, Guido and Wuppermann, Amelie, "Sage on the Stage: Is Lecturing Really All That Bad?" Education Next, Vol. 11, No. 3, Summer 2011.

[3] Friesen, Norm, "The Lecture as a Transmedial Pedagogical Form: A Historical Analysis," Educational Researcher, Vol. 40, No. 3, pp. 95-102, 2011. 
[4] Clift, Elayne, "From Students, a Misplaced Sense of Entitlement," The Chronicle of Higher Education, March 27, 2011.

[5] "Corporal Punishment and Paddling Statistics by State and Race," Center for Effective Discipline, July 1, 2010. Web. July 19, 2013.

[6] Sennett, Richard, Authority, Knopf, New York, 1980.

[7] Pace, Judith and Hemmings, Annette, "Understanding Authority in Classrooms: A Review of Theory, Ideology, and Research," Review of Educational Research, Vol. 77, No. 1, pp. 4-27, March 2007.

[8] Heifetz, Ronald, Leadership Without Easy Answers, Harvard University Press, 1998.

[9] Mortensen, Kurt, Maximum Influence: The 12 Universal Laws of Power Persuasion, AMACOM, 2004.

[10] Covey, Stephen M. R. and Merrill, Rebecca R., The SPEED of Trust: The One Thing That Changes Everything, Free Press, Reprint Edition, 2008. 